\title{
TRANSITION CRITERIA - FROM A PIT TO A CRACK
}

\author{
Tarun Goswami* and David W. Hoeppner \\ Quality and Integrity Design Engineering Center \\ Mechanical Engineering Department, University of Utah \\ Salt Lake City, Utah, 84112 USA
}

\begin{abstract}
A brief review of pitting, which is a localized corrosion process resulting from pitting and fatigue interaction has been conducted in this paper. The transition of a pit to a crack is a very important phenomenon occurring under PCF conditions. Various theories for transition of a pit to a crack were examined within the limits of present understanding and limitations of the models. The transition of a pit to a crack was also discussed for a variety of pit shapes utilizing the pit aspect ratios, defect size and linear elastic fracture mechanics, crack tip characterizing parameters such as Mode I stress intensity factor range. Pitting corrosion and fatigue interaction is presented in terms of a four-stage model hypothesized within electrochemical and mechanical components. Limited data are presented to support the hypotheses in this paper, which need to be validated with more data.
\end{abstract}

\section{INTRODUCTION}

As research on the aging of aircraft structures reveals earlier design ignorance, both fatigue and localized corrosion processes and their interactive mechanisms have attracted significant attention 11-10/. Corrosion was first thought to be a concern which could be corrected during inspection and subsequent maintenance. Only after the Aloha airline incident on April 28, 1988, were corrosion and its interaction with fatigue realized to be a potential failure mechanism of aircraft structures utilized in severe environments and load cycles. Corrosion is a time-dependent deformation mechanism which is deleterious and affects the residual strength properties of materials. If this residual strength decreases, the assessment of an aircraft's structural integrity presents new challenges for aircraft damage tolerance.

Following the 1988 incident, residual strength properties were investigated for a lead crack in the presence of multiple cracks and fastener holes $/ 11,12 /$. The residual strengths were found to decrease in

\footnotetext{
- Materials and Processes Group (178, MS 1), Cessna Aircraft Company, 2617 South Hoover Road, Wichita, KS 67215, Mechanical Engineering Department, Wichita State University, Wichita, KS 67260, USA.
} 
both cases in a range of $30 \%$. This problem could be more severe in the event of a lead crack interacting with a uniform distribution of pits. Therefore, this paper attempts to overview the mechanics of pitting when pitting interacts with fatigue. It is important to develop knowledge on this topic so that due considerations of pitting and multiple-site or multiple-element fatigue cracking can be evolved in the damage tolerance analysis of aircraft structures.

Economic reasons - the costs of fleet replacement versus fleet maintenance - are the main criteria for the use of aging aircraft fleets, in many cases beyond their design life. The localized corrosion can take place in many modes and types. Pitting, exfoliation and stress corrosion are a few candidate corrosion mechanisms observed in the structures of a tear down C/KC-135 aircraft $/ 13 /$. The most significant costs for the United States Air Force result from corrosion-related maintenance. Therefore, it is critical that corrosion prevention methodologies and technologies are developed to combat various corrosion effects on the structural integrity of aircraft. Pitting and exfoliation are two discontinuous corrosion mechanisms among other corrosion mechanisms, for example, crevice, filiform, etch corrosion, galvanic corrosion, intergranular corrosion, microbial corrosion, stress corrosion, hydrogen embrittlement, metallic mercury corrosion, fretting corrosion, and other types found in aircraft structures. Due mainly to the importance of pitting corrosion found in aircraft structures and the possibility that pits may behave as cracks, it is intended to review briefly pitting corrosion fatigue (PCF) and transition criteria from a pit to a crack and thus understand the metal fatigue behavior in aerospace structural materials.

Unlike general corrosion, which results in uniform removal of metal, pitting is a localized corrosion mechanism that occurs on the surface. Pitting is preferential and selective where it should occur. Therefore, pitting occurs along the grain boundaries, precipitates, metal and metallurgical discontinuities and inhomogeneities. Pitting also occurs where oxide film is thin or broken, activating the localized corrosion processes, the mechanics of which are time, temperature and environment dependent. In an aqueous environment, the metals corrode by electrochemical action by means of pitting. The whole of the metal surface contains regions of anodic as well as cathodic sites that dictate the electrochemical reactions and change with respect to time and other potential parameters. Thus, for a localized corrosion process like pitting to begin, knowledge of passive film and its mechanics is important within the following frameworks:

1) Chemical composition of passive film

2) Structure of passive film

3) Chemical and physical properties of passive film

4) Film coherence

5) Thickness of passive film and other areas.

The anodic surface film may be of continuous and discontinuous type. When electrolytic solution does not separate the electrode material entirely, they are called discontinuous films. They are porous and grow when the solution partially dissolves the film. Oxide film forms in the case of aluminum alloys, the development of which on the discontinuous metal surface depends on the applied anodic potential, whose value is limited by the oxygen evolution and other anodic reactions. 
The susceptibility of a metal or alloy to pitting is estimated by:

1) Determination of characteristic pitting potential

2) Determination of a critical pitting temperature

3) Measurement of the number of pits per unit area or weight loss

4) Determination of the lowest concentration of chloride ( $\left.\mathrm{Cl}^{-}\right)$ions causing pitting.

\section{PITTING KINETICS}

\subsection{Pit Nucleation and Propagation Mechanisms}

Increased susceptibility to 'pit' nucleation depends on local imperfections of passive film. Commercial metals contain a large amount of impurities and non-metallic inclusions, constituent particles and other forms. An estimate quotes the level of surface impurity in low alloy steels and stainless steels as high as $10^{3} / \mathrm{cm}^{2} / 13 /$ which was measured recently for 2024 and 7075 alloys and found to be nearly 3000 particles $/ \mathrm{mm}^{2}$. When the surface layer contains some chemical inhomogeneities or physical damage, localized attack takes place at those local points. Chemical inhomogeneities on the surface affect the surface passivity. A few regions susceptible to such attack are as follows:

1) boundaries between metal matrix and inclusions,

2) phases with different thermal expansion coefficients,

3) boundaries between the metal matrix and second phase particles,

4) inclusions having greater chemical reactivity from metal,

5) segregation of impurities along the grain boundaries,

6) flaws,

7) mechanical damage,

8) number of 'phase' interfaces, and

9) dislocation sites.

Particles of intermetallic phases are common sites for pit nucleation in the case of aluminum alloys. Aluminum contaminated with iron exhibits increased susceptibility to pitting. The presence of $\mathrm{FeAl}_{3}$ precipitates is believed to act as cathodes of local cells on the metal surface. The presence of a small number of copper ions in fresh water has been found to stimulate pit initiation by depositing a layer of $\mathrm{Cu}$ particles on $\mathrm{FeAl}_{3}$. Anions such as $\mathrm{SO}_{4}$ and $\mathrm{Cl}$, deposited on the oxide surface, react with the oxides and form water soluble salts of the type $\left(\mathrm{Al}\left(\mathrm{SO}_{4}\right)_{3}\right)$. Nucleation of pits, in the case of aluminum alloys, is also accelerated by the presence of flaws on the surface. Depending on the conditions of oxide film formation, flaws in various shapes, numbers, and densities may form. Anodic films contain few mechanical flaws but numerous residual flaws; the opposite is true in the case of air-formed films. Mechanical flaws are considered preferential sites for pit nucleation. Pits may also form in the absence 
of flaws. Pit nucleation is observed to be affected by the presence of blisters. Blisters occur along the oxide/metal interface and result in breaking of the film because of the high hydrogen gas pressure created in the blisters. They act as precursors to pitting.

The pitting corrosion process, in which the fatigue cycles were applied while the specimen was immersed in $3.5 \% \mathrm{NaCl}$ solution, and the cycles to pit nucleation are shown in Figure 1.

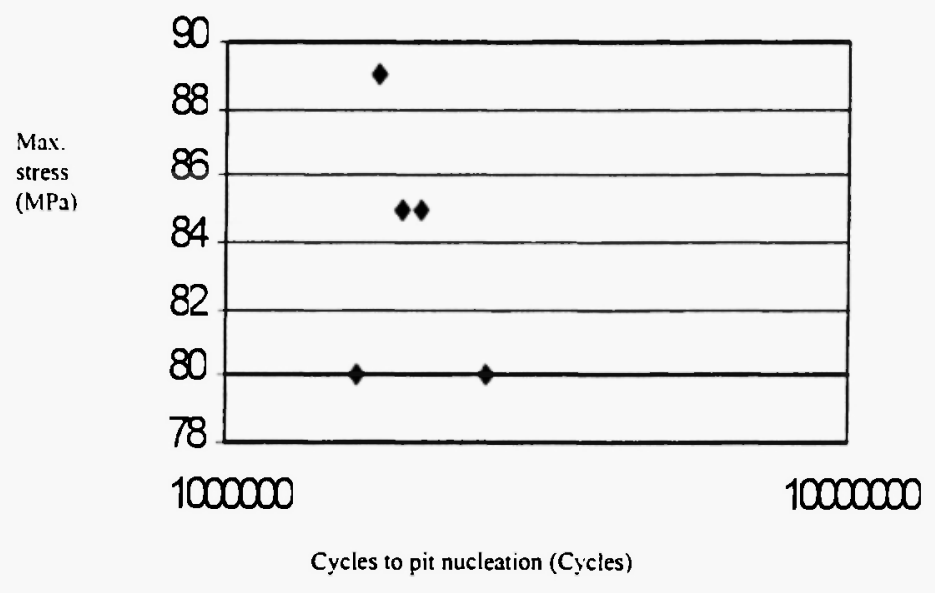

Fig. 1: Pitting corrosion fatigue cycles to pit nucleation.

\subsection{Pit Growth Mechanisms}

In the case of aluminum alloys, pit growth was also observed to follow a parabolic rate relation. Several other conceptual models have been proposed in the literature for pit growth, relating to charge transfer, diffusion-related mechanisms and Ohmic resistance controlled growth. The authors also reviewed various pit nucleation and growth mechanisms in separate papers /9,10/. Figure 2 shows the number of cycles to failure for the same specimens for which the pit nucleation was determined in Figure 1. It is interesting to note that the pit nucleation process is nearly one-third of the total life, while the pit growth and failure occurs in the remaining sixty percent of the life. It is during this phase that the pits link, grow and become a crack, which culminates in the failure.

\section{PITTING CORROSION RATE}

Few experimental data have been reported in the literature. The time necessary to form the first pit is mostly empirical in nature and depends on several variables. Concentration of $\mathrm{Cr}^{-}$ions in the solution is another factor. Reciprocal of induction time is hypothesized as a linear function of the $\mathrm{Cr}$ concentration. 


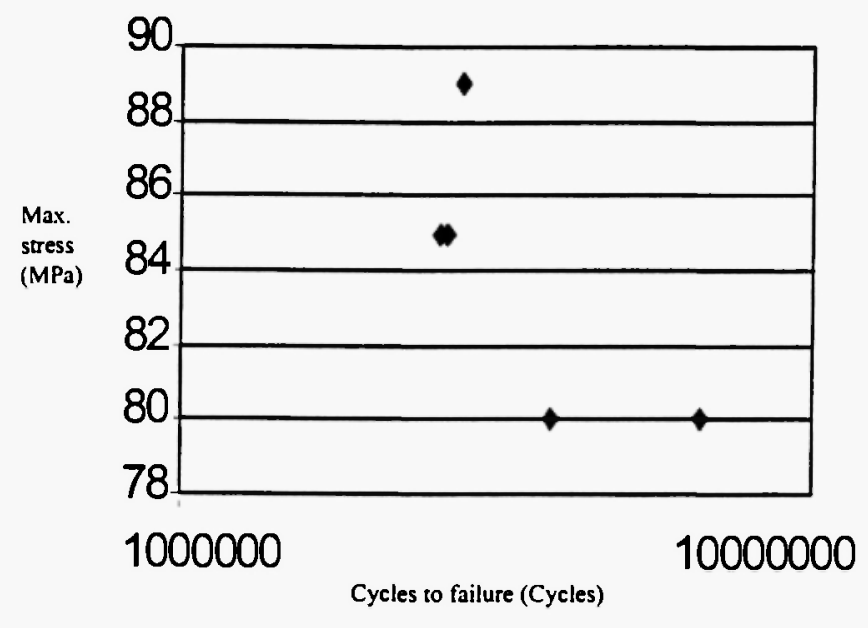

Fig. 2: Pitting corrosion fatigue cycles to pit growth.

Thus:

$\mathrm{l} / \tau=\mathrm{k}\left[\mathrm{Cl}^{-}\right]$

Below a certain critical value of $\mathrm{Cl}^{-}$concentration, pitting does not occur. There are conflicting opinions about this philosophy. In a $\log$ - $\log$ plot between the $\tau$ and $\mathrm{Cl}^{-}$concentration, the rate is proportional to the $n$-th power of the $\mathrm{Cl}^{\prime}$ ion concentration, where $n$ lies between 2 to $4.5 / 14$.

During an initial period, the corrosion rate is usually high because of the porous rust formation, which has poor protective properties in the case of ferrous materials. After an initial period of usually 1 to 5 years (depending upon local environment), the protective properties improve and corrosion rate decreases. The penetration depth increases with the time of exposure as shown in Fig. 3. A power law equation models the penetration depth and time of exposure in the following terms:

$$
\mathrm{P}=\mathrm{kt}^{\mathrm{n}}
$$

where: $\mathrm{p}$ is the penetration depth, $\mathrm{k}$ and $\mathrm{n}$ are material parameters and $\mathrm{t}$ is the time of exposure. The time dependent equations were used to relate the corrosion growth rates. The above relationship can also be expressed in terms of a bi-logarithmic diagram. In the author's laboratories a large bank of data were generated that can be schematically presented in terms of the relationship shown in Figure $3(a-b)$. these figures show that pit growth rate increases exponentially with respect to time in (a) whereas the depth of penetration increases exponentially after a predetermined time is elapsed (b). Earlier data, reported by the senior author, were in terms of a cubic power equation describing the pitting corrosion growth rates $/ 1 /$. However, this equation was used in context to address the pitting as well as fatigue processes in combination and showing the transition phenomenon. In the literature, penetration depth 


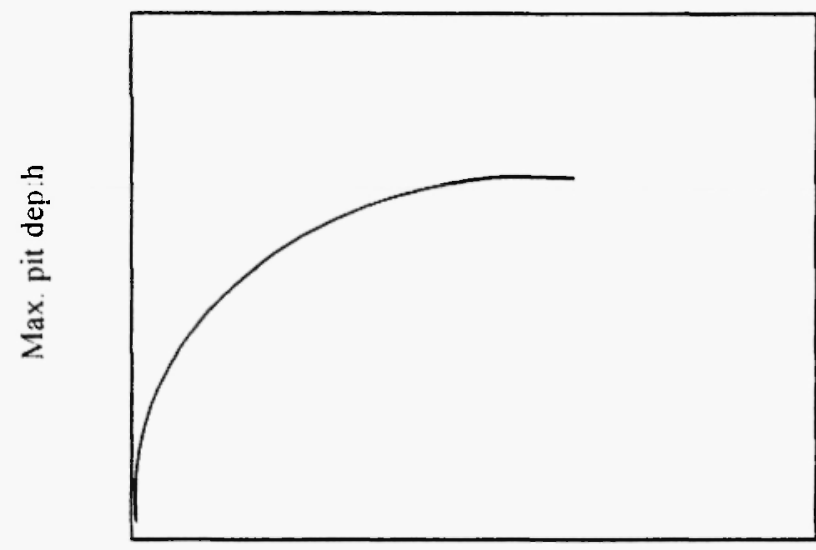

Exposure time

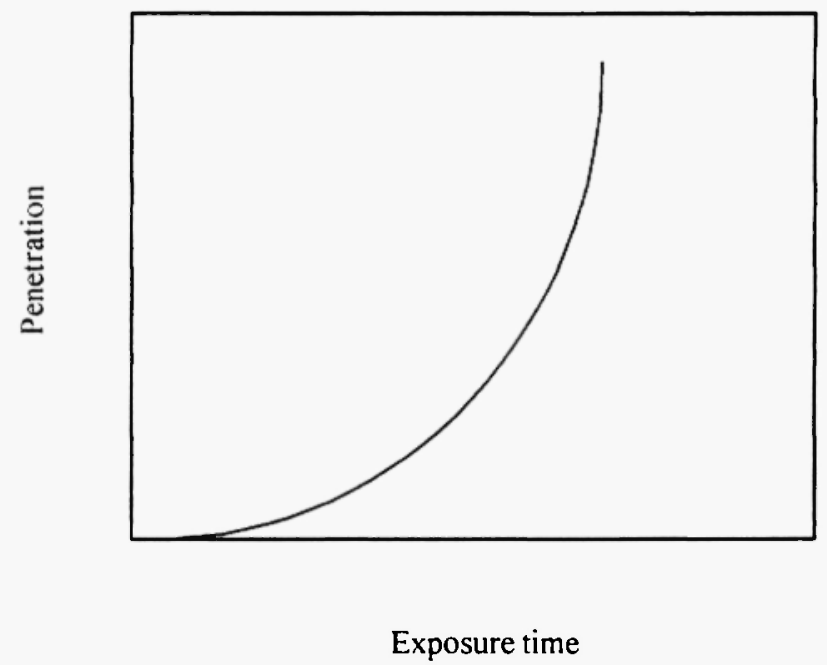

Fig. 3: Schematic diagram showing corrosion rates and penetration depth with exposure time.

for up to 20 or 30 years was proposed to be estimated from the extrapolation of the above relationship (Equation 2) obtained from the experimental results conducted over a period of 3-4 years. However, extrapolation of data obtained from 3 to 4 years of testing to over 25-30 years of material loss is quite questionable, mainly because the natural processes are different from accelerated testing. The underestimation of the corrosion rate may result from the change in the value of ' $n$ ' which depends upon the environment.

The rate of pit growth (depth) in the case of aluminum alloys is relatively high during the first few 
years of exposure. However, this rate decreases gradually so that the pit depth approaches nearly a constant value as shown in Fig. 3. An estimate shows that aluminum alloys containing $\mathrm{Cu}$ such as 2024-T3, 2024-T4, 7075-T6 and 7178-T6) will generally show four to 20 times the corrosion rates. However, another estimate quotes corrosion rates to be very small $-1 \mu \mathrm{m} / \mathrm{year}$ even in the worst polluted atmosphere. At higher $\mathrm{SO}_{2}$ concentrations (>0.01\%) only does severe corrosion occur.

\section{PITTING CORROSION FATIGUE BEHAVIOR}

Pitting corrosion fatigue is a combination of electrochemical and mechanical processes. The mechanical component is in terms of load-time fluctuations, which are dictated by frequency and stress ratio. The chemical component is in terms of the composition of the environment and its corrosiveness, $\mathrm{pH}$ level, other factors such as the presence of anions and cations, and the composition of the oxide film. Mechanical load-time fluctuations generate slip systems and the chemical component involves a break in the passive film formation. A summary of these matters is presented to introduce the reader to the role of the chemical processes that form the film and its subsequent performance in fatigue.

It is very important to understand oxide interference with the slip systems, produced under fatigue loading conditions. Mechanical properties of the oxide film were markedly improved in vacuum. The Young's modulus of the thin oxide film increased four times that of the oxide properties in air. This was attributed to the stronger film formed in vacuum, reducing the surface slip system; conversely, the weaker film formed in air is easily ruptured by emerging slip systems and crack nucleation, and propagation processes predominate.

Fatigue in the corrosive, aqueous environment, or pitting corrosion fatigue has been theorized in this paper within the following frameworks:

1) electrochemical attack and rupture of otherwise protective surface film

2) stress concentration created by pitting as a result of corrosive media

3) electrochemical attack at plastically deformed areas of metal with non-deformed metal acting as cathodes, crack nucleation and growth

4) lowering of surface energy of the metal due to environmental adsorption and increased propagation of micro-cracks, corrosion fatigue crack propagation.

The electrochemical aspect of pit nucleation, pit growth and pitting corrosion fatigue crack nucleation is not within the scope of this paper. Item No. 2) is being explored in some detail. Figure 4 shows a number of pit shapes that were made in aluminum alloys 2024-T3511 extrusions and plate (T351) materials under cyclic wet-dry immersion. Figure 4 (a-d) shows different pit shapes ranging from hemispherical to $\mathrm{V}$-shaped pits. Extensive areas in which pits linked and caused considerable material loss were also observed. Various pit shapes, shown in Fig. 4, concentrate stresses in a perpendicular direction to the loading axis. Intergranular corrosion seen in Fig. 4 (a) is a result of this feature. Fig. 4 (e) shows electrochemical attack on the plastically deformed crack tip, where the $\mathrm{NaCl}$ 
solution enters and causes localized dissolution. Crack tip blunting is observed in Fig. 4 (c) and (e). Metal dissolution occurs in preferred directions and planes in the perpendicular directions to the loading axis and via grain boundaries. Open crack tips are documented in the photomicrographs. Figure 4 (a-d) show cracking from various points from the pit periphery, which is contrary to the conventional approach in that cracking is assumed to occur from the base of a hemispherical pit.

Figure 4 (f-h) show low energy fracture features marked by cleavage from the point where a pit forms and its growth in the sample. A pit deforms by cleavage, under steady loading. The arrow in Fig. 4 (f) shows the bottom of a pit and the cleavage formation downwards. In this photomicrograph linear step bands are also seen. A higher magnification view shows cleavage planes and the evidence of cyclic chemical damage growth in alternate wet-dry immersion tests under $15 \mathrm{Ksi}$ steady loading. These features, under cyclic immersion (or wet-dry exposure), are very similar to fatigue striations being made under stress reversals, see Fig. 4 (g). This mode may be a critical one, as it may give rise to a situation in which micro-cracks as shown in Fig. $4(\mathrm{~g})$ may develop and propagate faster than

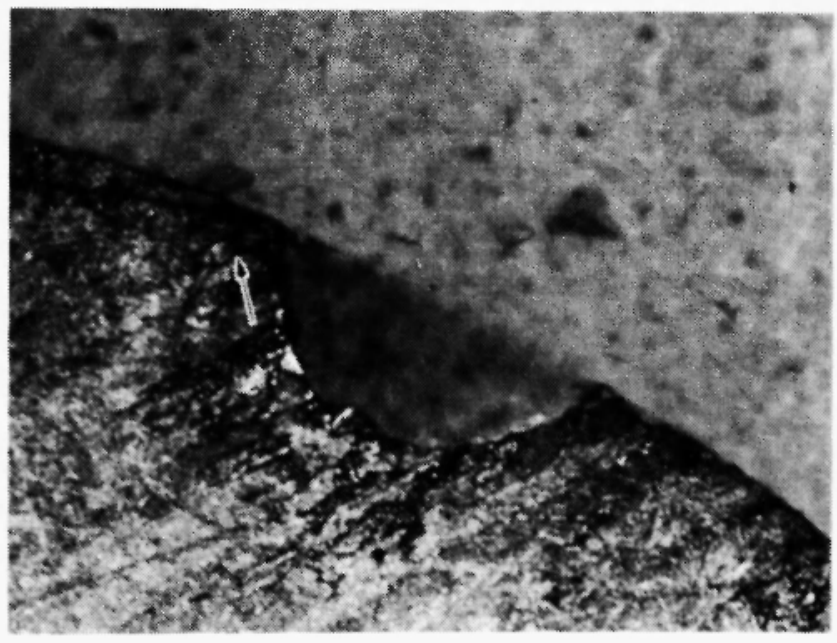

(a)

Fig. 4: Complex pit shapes in aluminum alloys:

a) hemispherical pit, note the cracking shown by arrow 100 microns)

b) V-shaped pit showing intergranular attack ( 100 microns)

c) extensive pitting showing intergranular corrosion attack ( 100 microns)

d) W shaped pit (- 200 microns)

e) intergranular pitting showing intergranular cracks shown by an arrow in (c) and (e) (- -200 microns)

f) pit depth on the fracture surface showing also cleavage

g) step marks on the cleavage planes showing cyclic corrosion damage growth

h) overloaded dimples. 
Fig. 4 continued

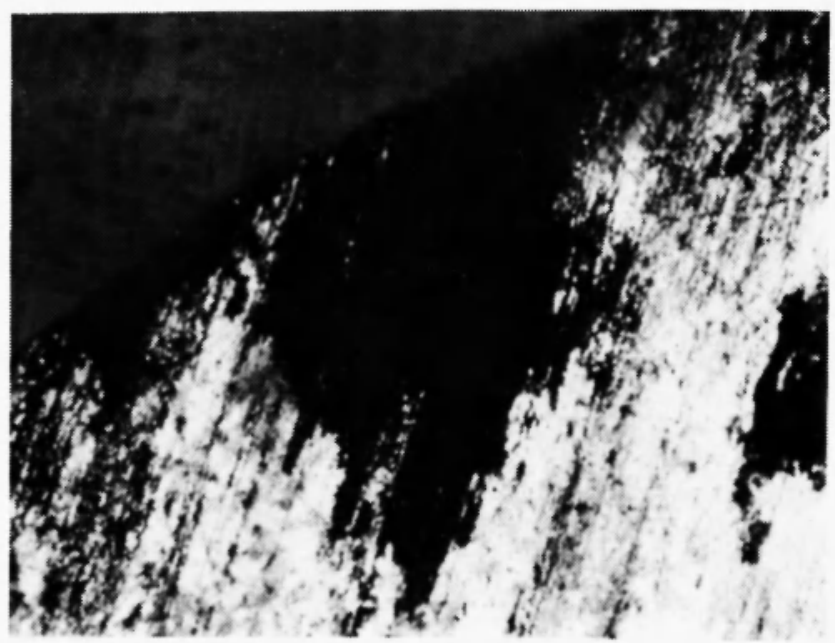

(b)

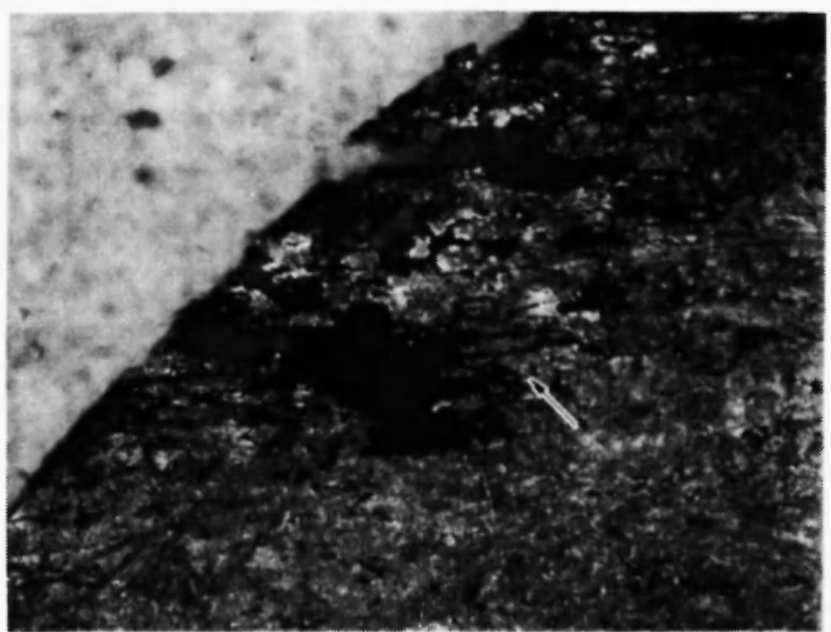

(c)

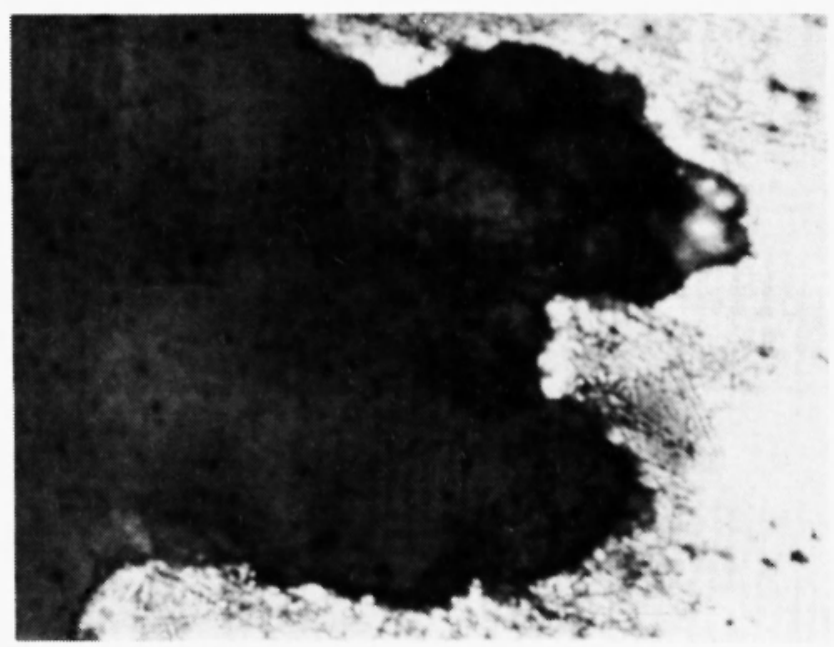

(d) 
Fig. 4 continued

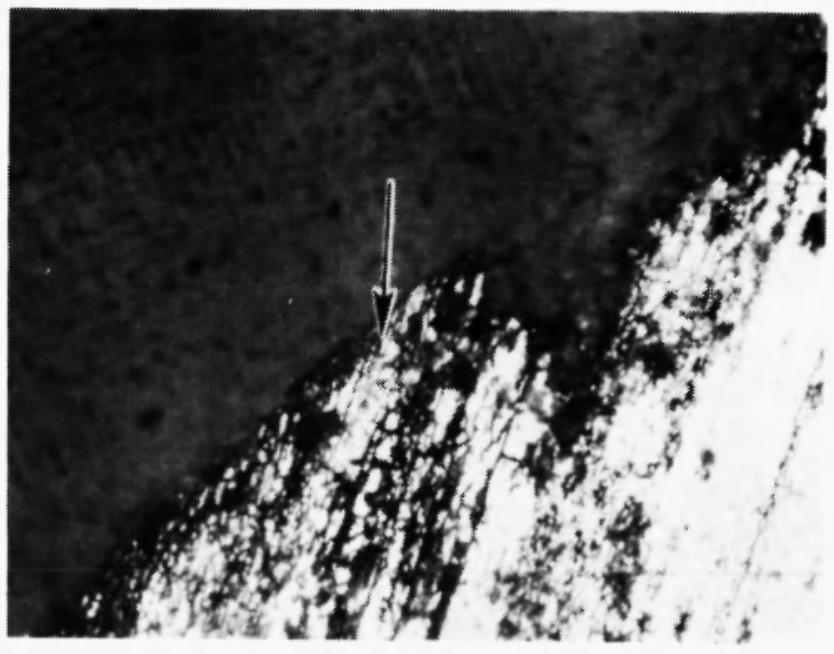

(e)

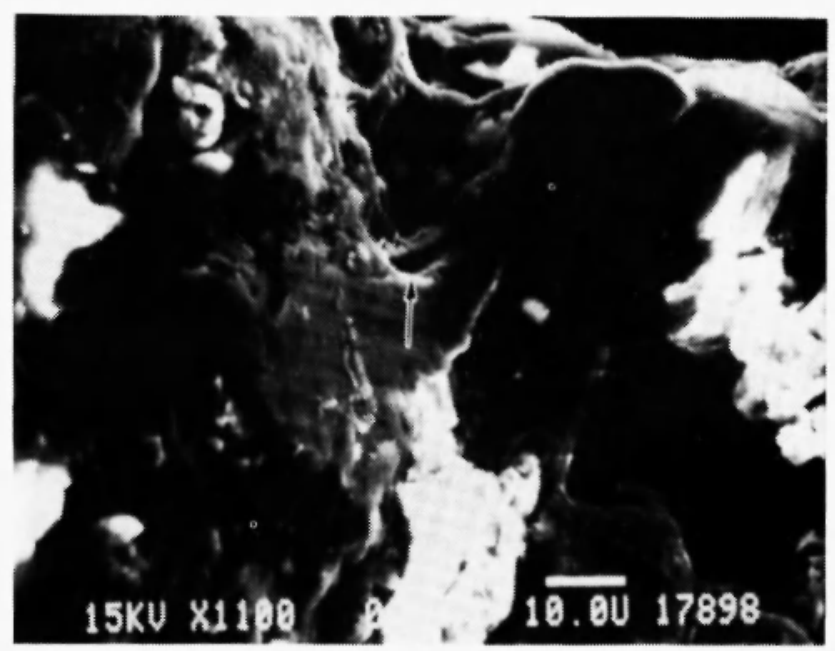

(f)

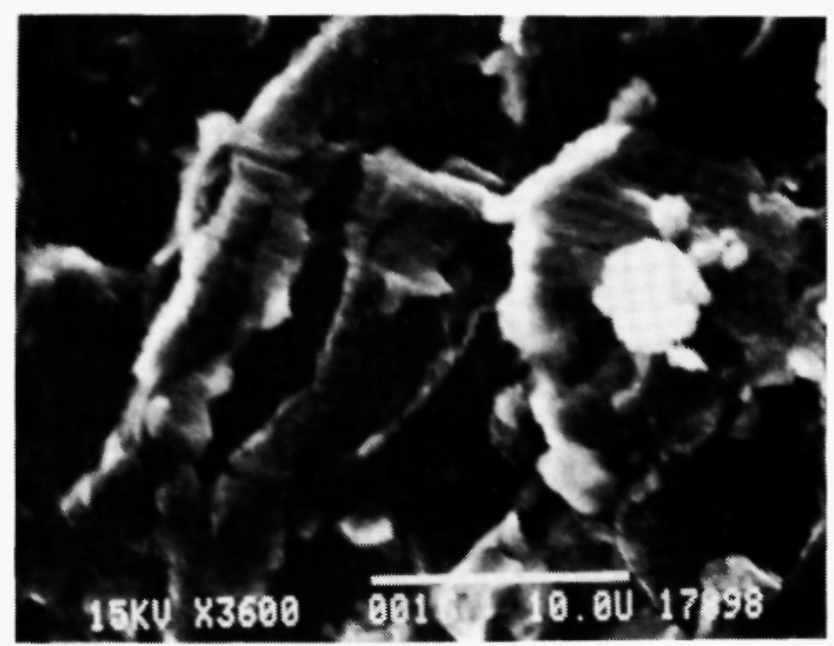

(g) 
Fig. 4 continued

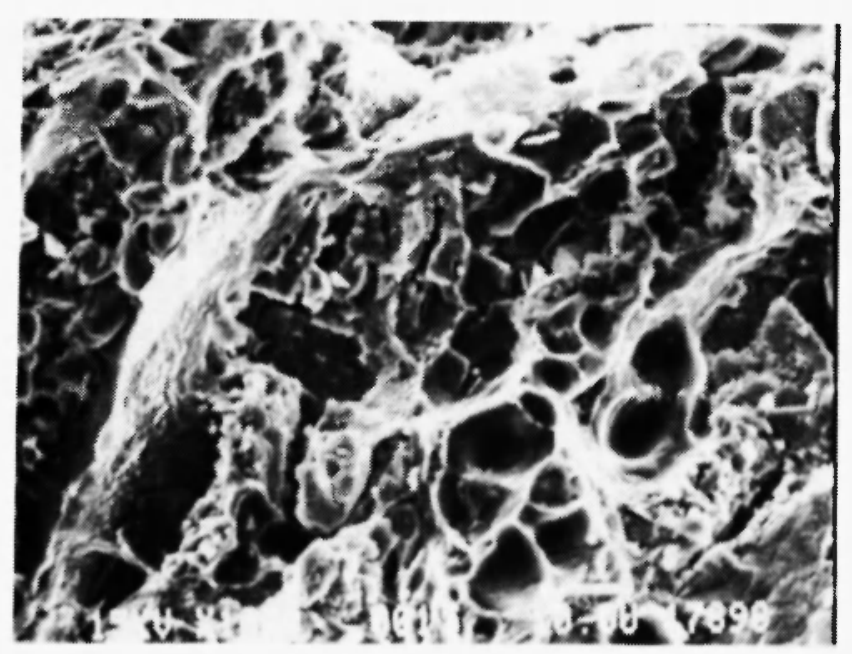

(h)

corrosion fatigue long cracks, and may require treatment similar to a corrosion fatigue "short" crack problem. Another implication of cleavage is to initiate a low-energy deformation process that may accelerate the fatigue crack growth at lower stress intensities. In the remaining area of the specimen, micro-void generation and coalescence are observed (h), which is a typical feature of overloading, being the mechanism for deformation and failure.

The pitting corrosion fatigue, which evolves in many stages through numerous mechanisms, has been conceptually proposed in this paper in terms of a six-stage electrochemical-mechanical process.

Stage I- the electrochemical processes take place. There are numerous variables, tabulated by the authors. Interactions among these variables are unknown and there is no published research discussing them. Electrochemical processes result in the pit formation, which is a time dependent event, where the above variables interact and accelerate the nucleation and growth of the pitting process.

Stage II-describes the interactions between electrochemical and mechanical processes. Anions and dislocations pile up in the vicinity of a defect and cause local dissolution leading to the formation of a pit. A combined anions-dislocations action accelerates the pit nucleation mechanism.

Stage III - describes several mechanisms such as the environment that may interact with microstructure. Depletion of precipitates takes place along the intergranular paths and corrosion takes place along those local regions. All these mechanisms may interact and cause damage collectively at a local point.

Stage $I V$ - considers the pit population in an area that may cause damage while interacting with fatigue and may nucleate cracks at multiple sites. Multi-site damage accounting for the surface discontinuities, discontinuous oxide film, and distributions of pits and cracks may result.

Stage $V$ - The above four stages are time dependent in nature; however, other variables in association with the chemical and/or mechanical processes accelerate the incubation time for pit formation. Once the pit or pits form, pit depth is a deciding criterion. In this stage stress concentration 
is accounted for, resulting from various pit shapes. At this point, pit growth is taken over by fatigue crack growth. This critical pit depth acts as the initial crack from which the short corrosion fatigue crack grows in Stage $V$.

Stage VI- describes the crack growth process either under mechanical (cyclic) loading conditions or under the actions of fatigue in corrosive environment by corrosion fatigue (CF).

\section{TRANSITION CRITERIA - FROM A PIT TO A CRACK}

\subsection{Modeling with Pit Shapes and Aspect Ratio}

Various pit shapes, shown in Figures $4(\mathrm{a}-\mathrm{g})$ have been documented as well as other shapes which were documented in the authors' laboratories. It is interesting to note that the deepest pits are made only sparingly; however, shallow pits are generated exponentially. If the frequency of occurrence and pit depth is plotted, a bell shape in the data was observed which is represented by a normal distribution. However, for other materials and test conditions the shape of the curve is not unique, in that the deepest pits and their frequency of occurrence remains the same, while other points vary randomly. The aspect ratio, pit diameter to depth ratio $(\mathrm{a} / 2 \mathrm{c})$, has been plotted in Figure 5 and a critical combination determined for a particular stress intensity factor range $(\Delta K)$.

$$
\Delta \mathrm{K}=2.24 \sigma_{\mathrm{a}}(\pi \mathrm{c} \alpha / \mathrm{Q})^{1 / 2}
$$

where $\sigma_{\mathbf{a}}$ is stress amplitude, $\alpha$ is aspect ratio, $\mathrm{Q}$ is shape factor.

Since pits form in many shapes such as hemispherical, U, W, V and other severe material losses

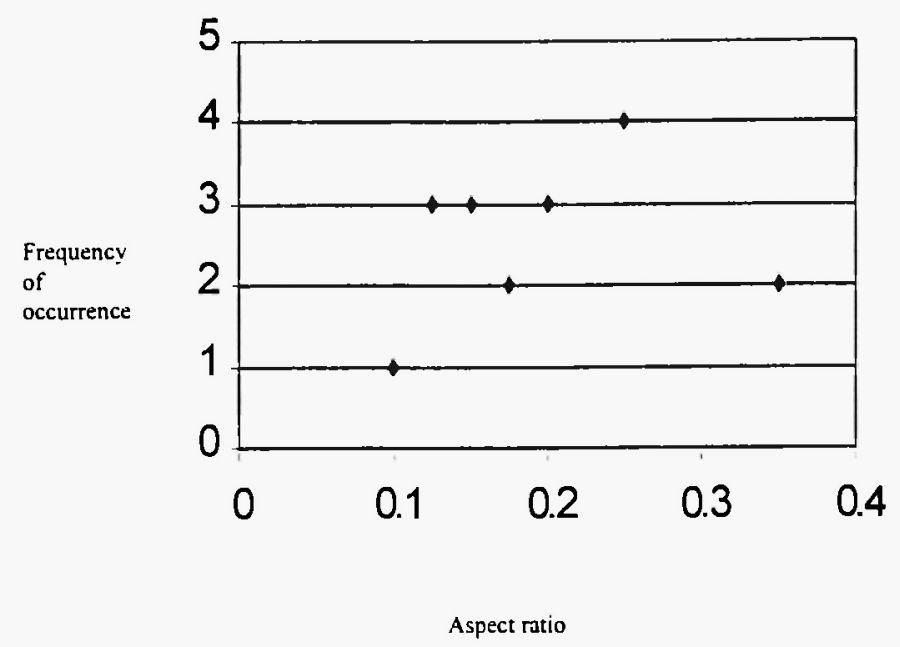

Fig. 5: Aspect ratio distribution in pitting corrosion fatigue. 
(shown in Figure 4) as a result of various mechanisms, transition of a pit to a crack depends on individual shape, stress field, and chemistry at the periphery of the pit. Murakami et al. $/ 15 /$ obtained the fatigue limit of specimens containing very small holes from 0.04 to $0.5 \mathrm{~mm}$. He also proposed empirical fatigue limit equations. The influence of pit shapes and mathematical models was presented by Kawai and Kasai /16/.

The aspect ratio, shown in Figure 5, plots the frequency of occurrence of a particular combination of pit length to width ratio in 2124-T851, aluminum alloy plate. It shows that frequency of occurrence of higher aspect ratios, in many instances, is less than one. However, aspect ratio as high as 10 may result in cases where severe material loss had taken place by pitting corrosion. A pit with higher aspect ratio transitions to a crack may be treated by Mode I LEFM models as represented by equation (3).

\subsection{Modeling with Mode I LEFM Models}

Several studies have been made in quantifying the minimum defect size such that the linear elastic fracture mechanics (LEFM) concepts can be applied. Brown and Srawley /17/ stated the defect size to be at least 50 times the size of the crack tip, plastic zone $\left(r_{p}\right)$. Following this, $170 \mu \mathrm{m}$ would be the minimum defect size for valid treatment by LEFM for a material with yield strength $630 \mathrm{MPa}$ and maximum stress intensity of $5 \mathrm{MNm}^{-3 / 2}$. Similar calculations of corrosion fatigue conducted by Clark $/ 18 /$ revealed minimum defect size to be $85 \mu \mathrm{m}$ for LEFM treatment. Chell $/ 19 /$ determined it to be 63 $\mu \mathrm{m}$ (plane strain) to $157 \mu \mathrm{m}$ (plane stress).

Hoeppner /1/ presented a conceptual model of predicting fatigue lives based upon pitting corrosion fatigue. He hypothesized the pitting corrosion process to be a possible environmental/deformation synergism that may explain the nucleation of Mode I cracking in materials subjected to the combined action of environment and alternating strains. An empirical pitting rate curve was determined and Weibull fit was derived on the crack growth data. Fatigue test results and the crack growth plots are shown in Figure 6 respectively for an aluminum alloy 2124-T851 plate material tested with $R=0.1$ in laboratory air containing a pit depth of $0.496 \mathrm{~mm}$ (shown by solid triangles in Figure 6). The other data set plotted in Figure 6 shows the crack growth behavior in the absence of initial pitting. It is clear from this behavior that pre-pitting alters the crack growth behavior where steep growth may occur in a given range of stress intensity factor. This behavior is of great concern to a damage tolerance analyst performing crack growth assessments using CRACKS 95 or other software packages. Since the difference is around an order of magnitude or higher, life obtained from pre-pitted areas may be scaled down linearly.

The test parameters utilized were representative frequency of $10 \mathrm{~Hz}$ and stress ratio of 0.1 and 0.05 respectively. Two specimen geometries (CT and MT respectively) were used, compact tension for the pre-pitted case and middle tension for the high humidity test. The data shows a change in crack propagation rates in the presence or absence of pitting. 


\section{Material 2124-T851 Plate}

(Solid triangles show pre pitting effect, and crack growth rates in the presence of a pit $0.496 \mathrm{~mm}$ deep and tested in lab. air (CT specimen) $\mathrm{R}=0.1$, the solid diamonds show crack growth rates in in high humidity, pre-cracked in lab. air (Middle Tension specimen) $R=0.05$ ).

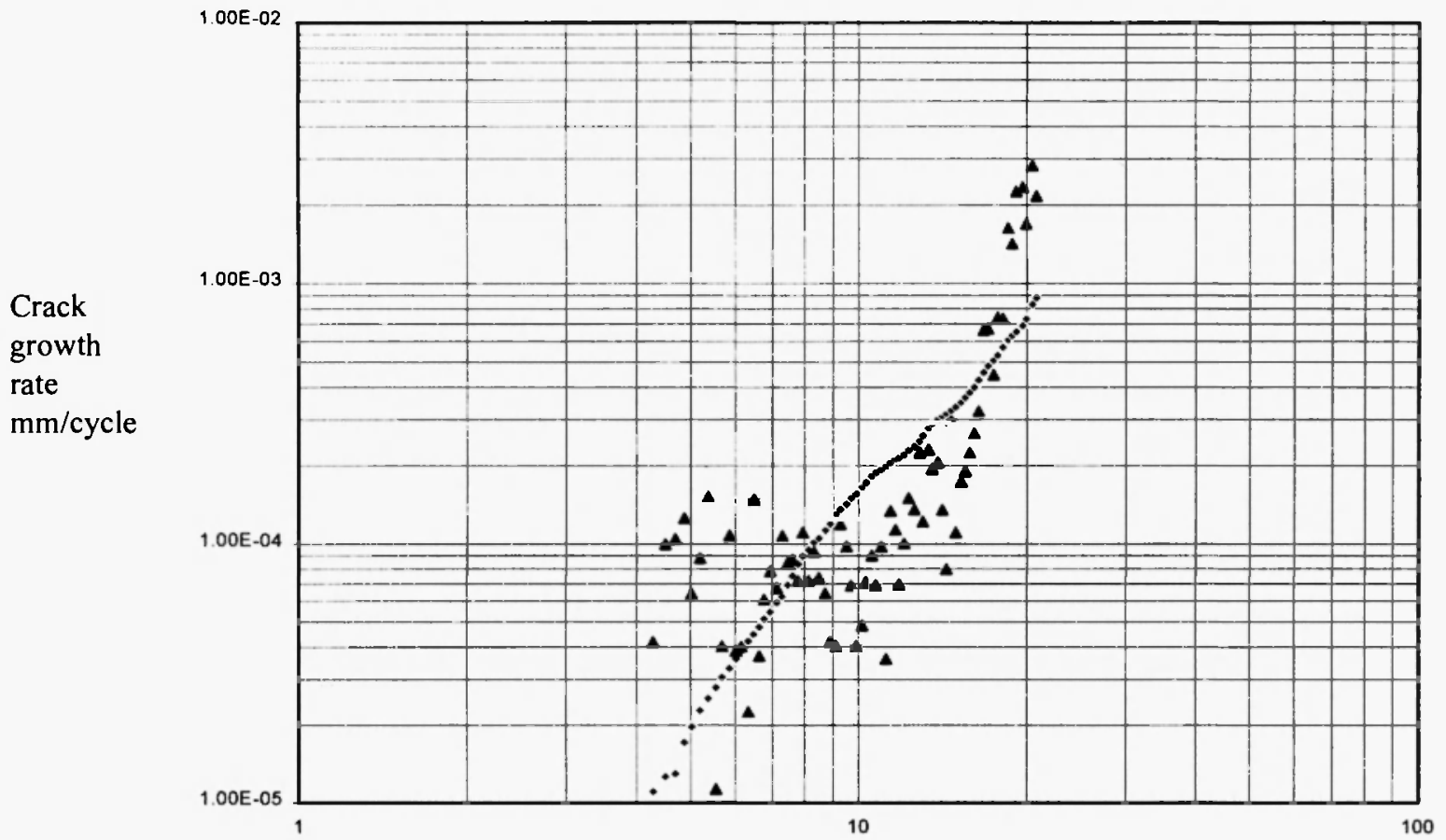

Mode I Stress Intensity Factor Range $(\Delta \mathrm{K}) \mathrm{MPa} \sqrt{\mathrm{m}}$

Fig. 6: Fatigue crack growth behavior of 2124-T851 aluminum plate alloy with or without pitting.

The effect of stress on the pit shape is of considerable importance $/ 20 /$. These were incorporated in a model $/ 21 /$ where pit diameter increased with time $(\mathrm{t})$ following the relation:

$$
\begin{aligned}
& (2 / 3) \pi r^{3}=B t \\
& r=t^{1 / 3}
\end{aligned}
$$

where $r$ is the radius of hemispherical pit and $B$ constant bulk dissolution rate.

It was assumed $/ 21 /$ that the volume increased proportionally to the time $(\mathrm{t})$. Change of pit diameter and its measurement with respect to time and fatigue cycles are very rarely done, since there are two reference cycles and time. Kondo /21/ used the criterion of Newman and Raju /22/ in calculating the stress intensity for a critical pit by assuming a pit, a crack. Another assumption made 
$121 /$ refers to the transition from pit growth to the crack, occurring when fatigue crack growth rate exceeds the pit growth rate. Corrosion pit growth rates can be expressed empirically in the following form:

$$
C=C_{p} t^{1 / 3}=C_{p}(N / f)^{1 / 3}
$$

where $C_{p}$ is the coefficient, $t$ is the time, $N$ is the number of stress cycles and $f$ is the frequency, $2 c$ is the pit diameter.

The pit growth rate $(\mathrm{dc} / \mathrm{dN})$ is expressed as follows:

$$
d c / d N=(1 / 3) C_{p} f^{1 / 3} N^{-2 / 3}=(1 / 3) C_{p}^{3} f^{-1} c^{-2}
$$

These equations can be combined in the following relationship:

$$
\mathrm{dc} / \mathrm{dN}=(1 / 3) \mathrm{C}_{\mathrm{p}}^{3} \mathrm{f}^{-1} \alpha^{2} \pi^{2} \mathrm{Q}^{-2}\left(2.24 \sigma_{\mathrm{a}}\right)^{4} \Delta \mathrm{K}^{-4}
$$

Figure 7 shows the pit growth rate $\mathrm{dc} / \mathrm{dN}$ schematically. As the pit grows, the pit growth rate decreases. At a transition point the fatigue crack growth process takes over the pit growth. The point of intersection of the two behaviors describes the critical pit condition. The boundaries of the pit growth and crack growth and where crack growth precedes the pit growth is shown in Fig. 8.

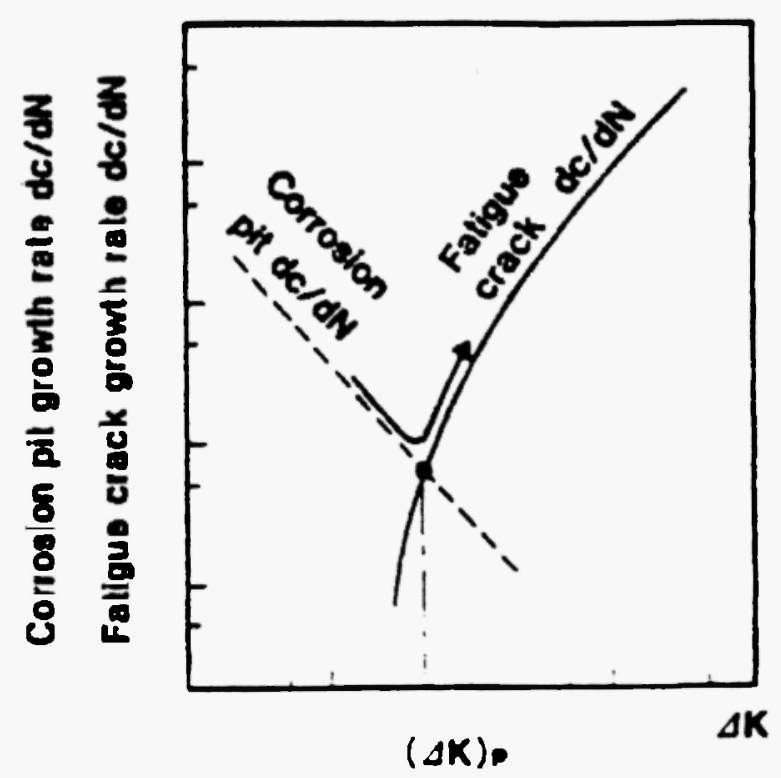

Fig. 7: Corrosion pit growth, fatigue crack growth and transition behavior. 


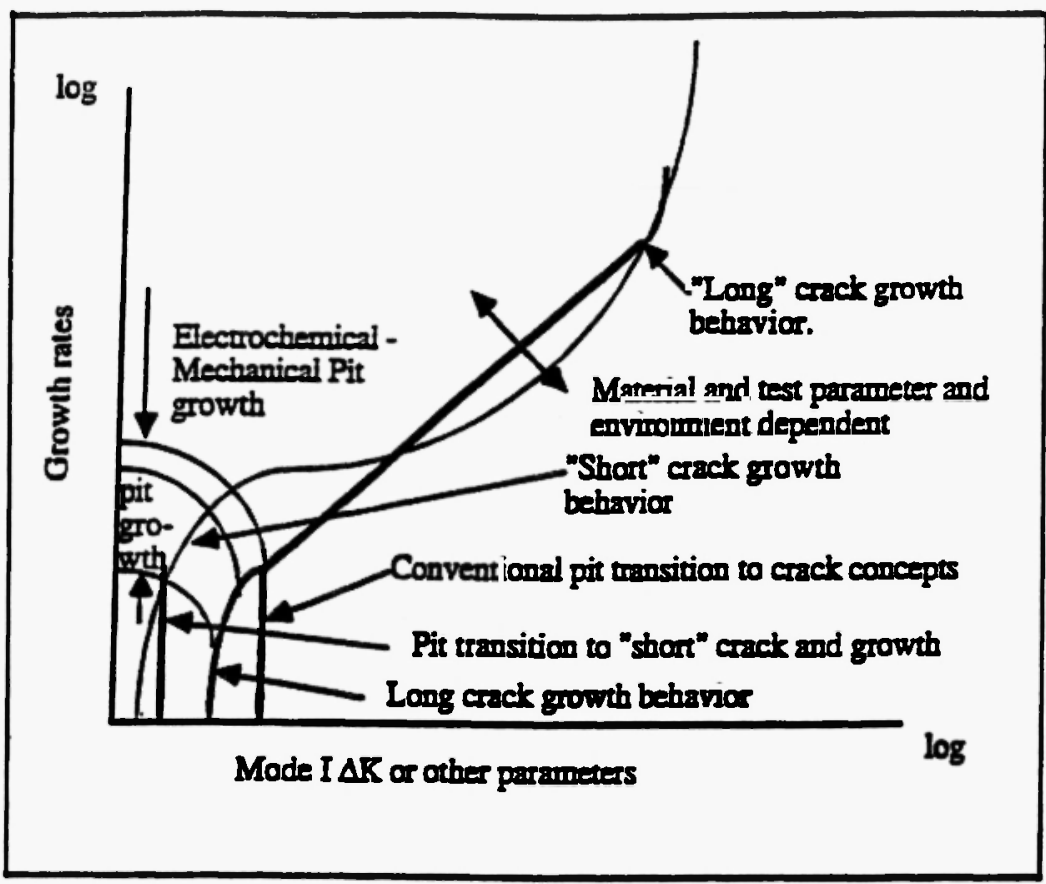

Fig. 8: Schematic representation of pit transition to crack concepts.

\section{DISCUSSION AND CONCLUDING REMARKS}

Extending the life of aging aircraft structures presents new challenges to the scientific community as well as those who perform damage tolerance analyses. There have been many reports in the literature describing the environmental effects and corrosion and corrosion fatigue behaviors, where tests are conducted in sea water, typically in a range of $3.5 \% \mathrm{NaCl}$, and a typical $\mathrm{pH}$ value. The corrosion and fatigue interactions in an aircraft structure are very complex problems. The environment in which a particular fleet operates is of considerable importance. Depending upon these and other factors localized corrosion damage will take place. In the fuselage sections of the tear down structure of a $\mathrm{C} / \mathrm{KC} 135$ aircraft after 30 years of service pitting, exfoliation and intergranular cracking were observed.

The detection and quantification of hidden corrosion are two important issues. Microscopic quantification of corrosion by measuring the pit depth and/or weight loss applies to very small specimens. The quantification and detection of corrosion in aircraft structures are not yet fully resolved. There are doubts associated with the published results on the pitting rate and its extrapolation to the equivalent of 30 years of exposure, and with the use of those data in damage tolerance analysis. Naturally corroded samples from the tear down $\mathrm{C} / \mathrm{KC} 135$ structure exhibited severe material loss. Such observations contradict the procedures proposed early in 1960 . 
A threshold stress intensity factor was derived $/ 23,24$ / from the pits. Frequency of occurrence and aspect ratio curves show an aspect ratio of 0.7 or 0.75 ; this was incorporated into the model, which has the following form:

$$
\Delta \mathrm{K}_{\mathrm{o}}=0.77 \Delta \sigma_{\text {lim }} \vee(\pi \mathrm{a})
$$

where $\Delta \sigma_{\text {him }}$ is overall surface stress range at the fatigue limit.

Some of these values are tabulated in reference $/ 8$. From the discussions above, the aspect ratio is very important in determining the threshold stress intensity factor, which is independent of pit depth in a range of 70 to $250 \mu \mathrm{m}$. The above equations can be utilized to determine the range of pit parameters. For a range of pit depth combinations from 75 to $450 \mu \mathrm{m}$ the threshold stress intensity factor range was found to be from 1.25 to $2.47 \mathrm{MPa} \mathrm{m}^{1 / 2}$.

In summary, pitting is a very important localized corrosion mechanism. Transition of a pit to a crack for aluminum alloys under different conditions is not yet fully understood /1-24/. Understanding of physics in terms of 'electrochemical' aspects and fatigue will help to determine empirical factors and their consideration in the damage tolerance codes and procedures so that life assessment can be performed. Pit size and shapes are important since they govern the aspect ratio and threshold stress intensity criterion and the transition from a pit to a fatigue crack. More work is recommended so that these boundaries can be generated for the aging aircraft's structural materials.

\section{ACKNOWLEDGEMENT}

The work reported in this paper was conducted at the University of Utah, Department of Mechanical Engineering at the Quality and Integrity Design Engineering Center, Salt Lake City. The Air Force Office of Scientific Research, Tinker Air Force Base, Boeing Defense and Space Group, Wichita Division, ARINC Research and other agencies provided partial financial assistance. The authors are grateful to Mr. Don Nieser, Tinker Air Force Base, Oklahoma City, for providing access to $\mathrm{C} / \mathrm{KC}-135$ tear down evaluation programs and supporting our efforts in the understanding of pitting related research.

\section{REFERENCES}

1. D.W. Hoeppner, ASTM STP No. 675, 1979; p. 841.

2. W. Wallace, D.W. Hoeppner and P.V. Kandachar, NATO Advisory Group for Aerospace Research and Development, AGARDograph No. 278, 1985. 
3. R.P. Gangloff and A. Turnbull, in: Modelling Environmental Effects on Crack Growth Process, R.H. Jones and W.W. Gerberich (Eds.), Met. Soc. Inc., 1985; p. 55.

4. K. Endo, K. Komai, T. Fujimoto and Y. Matsuda, JSME, 23, 807 (1980).

5. F.P. Ford and M. Silverman, Corrosion, 36, 597 (1980).

6. R.P. Wei and J.D. Landes, Mater. Res. \& Standards, 9, 25 (1969).

7. D.J. Duquetee and H.H. Uhlig, Trans. $A S M, 62,839$ (1969).

8. T.C. Lindley, P. Mclntyre and P.J. Trant, Metals Tech., 9, 135 (1982).

9. D.W. Hoeppner and T. Goswami, in: Proc. USAF Structural Integrity Program Conference, WL-TR-94-407, T. Cooper (Ed.), 1993; p. 219.

10. T. Goswami and D.W. Heoppner, in: Proc. Structural Integrity in Aging Aircraft, AD-Vol. 47, C.I. Chang and C.T. Sun (Eds.), ASME, 1995; p. 129.

11. T. Swift, in: Proc. $5^{\text {th }}$ International Conference on Structural Airworthiness of New and Aging Aircraft, DGLR Bericht 93-02, 1993; p. 133.

12. J.R. Maclin, in: Proc. International Conference on Aging Aircraft and Structural Airworthiness, NASA Conference Publication 3160, 1992; p. 67.

13. T. Goswami and D.W. Hoeppner, Unpublished work at the Quality and Integrity Design Engineering Center, University of Utah, Salt Lake City, 1992-1998.

14. T.P. Hoar and W.R. Jacob, Nature, 216, 1299 (1967).

15. Y. Murakami and M. Endo, Engg. Fract. Mech., 17 (1), I (1983).

16. S. Kawai and K. Kasai, Engg. Fract. Mech., 8, (2), 115 (1985).

17. W.P. Brown and J.E. Srawley, ASTM STP 410, 1967.

18. W.G. Clark Jr., ASTM STP 601, p. 138, 1976.

19. G.G. Chell, Central Electricity Res. Laboratories Report No. RD/L/R 2007, 1980.

20. C. Masuda, H. Hirukawa, S. Nishijima and T. Abe, Trans. JSME, AA52, (480), 1764 (1986).

21. Y. Kondo, Corrosion, 45 (1), 7 (1989).

22. J.C. Newman Jr. and I.S. Raju, NASA Technical Paper 1578, 1978.

23. P.M. Scott and T.W. Thorpe, Report UKAEA Harwell AERE-R10104, 1981.

24. R.T. Hartranft and G.C. Sih, Methods of Analysis of Crack Problems, Amsterdam, 1973; p. 179. 